\title{
Corrosion and Inhibition Effects of Mild Steel in Hydrochloric Acid Solutions Containing Organophosphonic Acid
}

\author{
Manish Gupta, ${ }^{1}$ Jyotsna Mishra, ${ }^{1}$ and K. S. Pitre ${ }^{2}$ \\ ${ }^{1}$ Department of Chemistry, Scope College of Engineering, Bhopal, Madhya Pradesh 462047, India \\ ${ }^{2}$ Department of Chemistry, Dr. H.S. Gour University, Sagar, Madhya Pradesh 470003, India \\ Correspondence should be addressed to Jyotsna Mishra; j_mishrall@rediffmail.com
}

Received 26 February 2013; Revised 22 June 2013; Accepted 23 July 2013

Academic Editor: Vesna Mišković-Stanković

Copyright (c) 2013 Manish Gupta et al. This is an open access article distributed under the Creative Commons Attribution License, which permits unrestricted use, distribution, and reproduction in any medium, provided the original work is properly cited.

\begin{abstract}
A study has been made on the mechanism of corrosion of mild steel and the effect of nitrilo trimethylene phosphonic (NTMP) acid as a corrosion inhibitor in acidic medium, that is, $10 \% \mathrm{HCl}$ using the weight loss method and electrochemical techniques, that is, potentiodynamic and galvanostatic polarization measurements. Although corrosion is a long-time process, but it takes place at a faster rate in the beginning which goes on decreasing with due course of time. The above-mentioned methods of corrosion rate determination furnish an average value for a long-time interval. Looking at the versatility and minimum detection limit of the voltammetric method, the authors have developed a new voltammetric method for the determination of corrosion rate at shorttime intervals. The results of corrosion of mild steel in $10 \% \mathrm{HCl}$ solution with and without NTMP inhibitor at short-time intervals have been reported. The corrosion inhibition efficiency of NTMP is $93 \%$ after $24 \mathrm{~h}$.
\end{abstract}

\section{Introduction}

Mild steel is a major material of construction. It is extensively used in chemical and allied industries for handling alkalis, acids, and salt solutions [1]. Hydrochloric ( $\mathrm{HCl}$ ) acid is the solvent most often employed for chemical cleaning. It attacks a wide range of scales [2]. Nitrogen compounds constitute the largest class of inhibitors for hydrochloric acid [3] solution. During the past decade a number of polymers and phosphonates have been used in different inhibitor compositions in aqueous and acid solutions [4]. They form stable complexes and some times act as detergent also. The role of inhibitor is the prevention of the adsorption of aggressive anions and reduction of the dissolution rate of the passivating oxide. In the present paper we have studied the action and effectiveness of nitrilo trimethylene phosphonic acid (NTMP) as inhibitor for corrosion of carbon steel in $(10 \% \mathrm{HCl})$ acid solution.

Most of the methods are proposed in the field of corrosion rate determination, but they furnish an average value for a long-time interval [5]. Looking at the sensitivity and minimum detection limits $[6,7]$ of polarographic techniques, that is, direct current polarography (DCP), differential pulse polarography (DPP), and voltammetric, that is, differential pulse anodic stripping voltammetric (DPASV) method has been used to determine the corrosion rates and inhibition efficiency of NTMP of mild steel in $10 \% \mathrm{HCl}$ solution at short time intervals. Significantly it has also been possible to determine the corrosion rates simultaneously with respect to $\mathrm{Fe}(\mathrm{II})$ and $\mathrm{Fe}(\mathrm{III})$ which is not possible using other methods prevalent in the field. Their results have been discussed in the paper.

\section{Experimental}

2.1. Chemicals and Reagents. All the chemicals used were of anal R/BDH grade. The inhibitor (NTMP, 99.9\% pure) was synthesized at the Central Research Institute For Chemistry, Budapest, Hungery. Experiments were carried out in 10\% $\mathrm{HCl}$ solution. Mild Steel specimens $50 * 20 * 4 \mathrm{~mm}$ size having composition (C-0.23\%, P-0.05\%, S- $0.055 \%$ ) were used in experiments. These specimen were polished following the usual procedure [8]. All the measurements were carried out at room temperature $30^{\circ} \mathrm{C}$.

2.2. Gravimetric Measurements. After abrasion with 600 grit papers all samples were degreased with acetone, pickled 
TABLE 1: Results of planned interval test (PIT) on mild steel in $10 \% \mathrm{HCl}$ solution.

\begin{tabular}{|c|c|c|c|c|c|c|}
\hline \multirow[b]{2}{*}{ S. no. } & \multirow[b]{2}{*}{ Period } & \multicolumn{2}{|c|}{ Without inhibitor } & \multicolumn{2}{|c|}{ With inhibitor } & \multirow[b]{2}{*}{$\%$ inhibition } \\
\hline & & $\begin{array}{c}\text { Concentration } \\
\left(\text { milligram } \times 10^{2}\right)\end{array}$ & $\begin{array}{c}\text { Corrosion rate } \\
\text { (milligram centimeter } \\
\text { hour }^{-1} \times 10^{2} \text { ) }\end{array}$ & $\begin{array}{c}\text { Concentration } \\
\left(\text { milligram } \times 10^{2}\right)\end{array}$ & $\begin{array}{c}\text { Corrosion rate } \\
\text { (milligram centimeter } \\
\text { hour }^{-1} \times 10^{2} \text { ) }\end{array}$ & \\
\hline 1 & $A_{1}(3 \mathrm{~h})$ & 18.96 & 21.2 & 5.21 & 5.82 & 72 \\
\hline 2 & $A_{t}(22 \mathrm{~h})$ & 31.05 & 4.70 & 6.32 & 0.96 & 79 \\
\hline 3 & $A_{t+1}(22+3 \mathrm{~h})$ & 34.58 & 4.64 & 6.40 & 0.85 & 82 \\
\hline 4 & $B(3 \mathrm{~h})$ & 3.33 & 3.72 & 0.50 & 0.50 & 96 \\
\hline 5 & $A_{C}(3 \mathrm{~h})$ & 3.53 & 3.94 & 0.08 & 0.08 & 97 \\
\hline
\end{tabular}

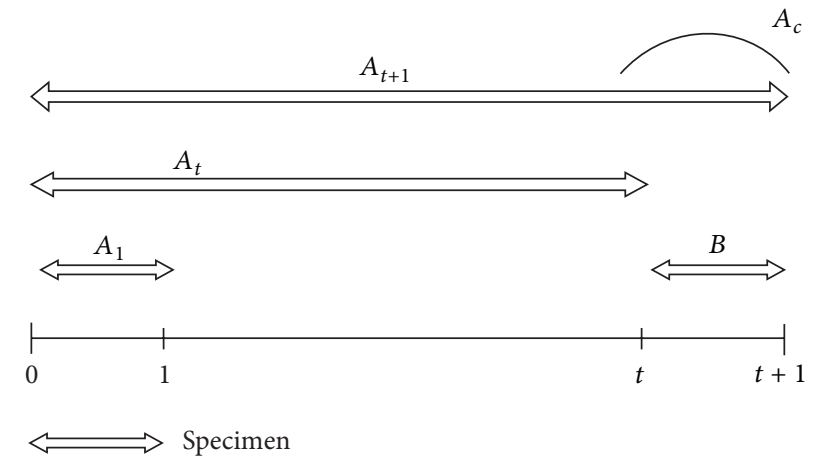

FIGURE 1: Procedure of "planned interval test" technique identical specimen all placed in the some corrosive fluid imposed conditions of the test kept constant for entire time $A_{t+1}$. The terms $A_{l}, A_{t}, A_{t+1}$, and $B$ represent corrosive damage experienced by each specimen, $A_{c}$ is calculated by substracting $A_{t}$ from $A_{t+1}$.

in $15 \% \mathrm{HCl}$ solution, washed under running tap water, rinsed in distilled water, dried with acetone, and weighed. The variation of solution corrosiveness and corrosion rate as a function of time was investigated using the planned interval test technique [8]. Three weighed specimens were introduced into the solution. These were removed after various exposure times, giving damage factors referred to as $A_{1}$ for $22 \mathrm{~h}$, $A_{t}$ for $3 \mathrm{~h}$, and $A_{t+1}$ for $25 \mathrm{~h}$. A fourth specimen $(B)$ was introduced into the cell for the last period for $3 \mathrm{~h}$. The values of $A_{1}, B$ (measured values) and $A_{c}$ (calculated from $A_{1}$, and $A_{t+1}$ ) relate to the same testing period, but under different conditions. This technique is schematically illustrated in Figure 1.

After each experiment, the specimens were cleaned by washing in water and acetone then weighed; from these measurements the corrosion rates were calculated. The methods of evaluating the results and combinations of situations are summarized in Table 1.

2.3. Potentiodynamic Polarization Measurement. The specimen was molded into epoxy resin in order to cover the sides of the rod, while the circular cross section area of the cylinder was exposed to the solution. The specimen was polished and washed with distilled water before the experiment. The potential scan path was $50 \mathrm{mV} / 5 \mathrm{~min}$. The observed current was plotted against applied potential.
2.4. Galvanostatic Polarization Measurement. The galvanostatic polarization measurements were also made in $10 \%$ $\mathrm{HCl}$ solution on $10 \mathrm{~cm}^{2}$ cylindrical surface of the working electrode. Saturated calomel electrode (SCE) was used as a reference electrode. An AJCO Electronics (model VT S5016) attached to a multiplex galvanometer was used for the galvanostatic studies. The polarization currents were measured by using a cycle of $10 \mathrm{~s}$ and changing potential by $10 \mathrm{mV}$. Both anodic and cathodic cycles were used alternately. The corrosion current density was plotted against the applied potential.

2.5. Voltammetric and Polarographic Measurements. An Elico Pulse Polarograph (model CL-90) was used for these studies. A cell consisting of three electrodes, namely, saturated calomel electrode as a reference, a coiled platinum wire as an auxiliary, and a dropping mercury electrode (for DCP and DPP)/glassy carbon fiber electrode (for DPASV) as a working electrode, was used. The test specimens were polished as discussed earlier, and one such specimen was suspended in $10 \% \mathrm{HCl}$ solution at room temperature $\left(25^{\circ} \mathrm{C}\right)$. Nitrogen gas was bubbled throughout the solution through the experiment to avoid the oxidation of dissolved Fe(II) to $\mathrm{Fe}$ (III). A definite aliquot of the solution was withdrawn from the test solution at different intervals $(5,10,20 \mathrm{~min}$, 1,2 , and $24 \mathrm{~h}$ ), and polarograms and voltammograms were recorded in deaerated $0.1 \mathrm{M}$ ammonium tartrate $+0.001 \%$ gelatin at $\mathrm{pH} 9.0 \pm 0.1$. The $\mathrm{pH}$ of the test solution was adjusted using ammonia solution. A similar experiment was performed using $170 \mathrm{mg} / \mathrm{L}$ NTMP in $10 \% \mathrm{HCl}$ solution.

\section{Results and Discussion}

3.1. Gravimetric Measurement. The results of weight loss determination by gravimetric are shown as corrosion rates in the presence and absence of NTMP inhibitor in Table 1. The data obtained for the periods $A_{1}$ and $B$ suggest that solution corrosiveness increases in the base solution $(10 \%$ $\mathrm{HCl})$ while in the presence of NTMP it decreases $\left(B<A_{1}\right)$. The higher corrosivity of the solution can be attributed to the increase in concentration of iron ions in the solution. This suggests that NTMP molecules reduce the stimulating effect of iron ions. By comparison with the data relating to $B$ and $A_{c}$ it can be concluded that metal corrodibility decreases $\left(A_{c}<B\right)$ as a function of time in the presence of the NTMP. 


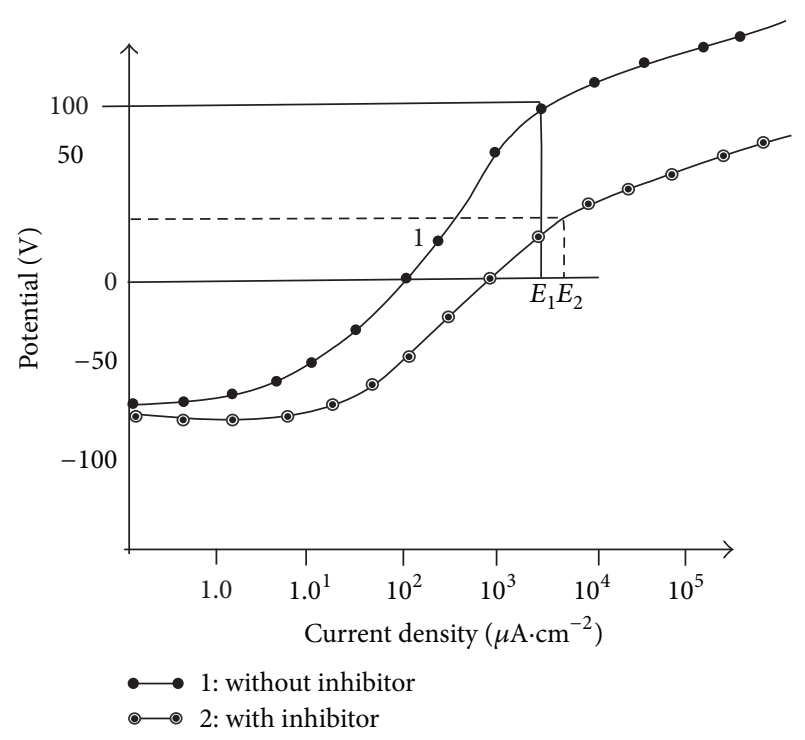

Figure 2: Potentiodynamic polarization curves of carbon steel in $10 \% \mathrm{HCl}$ with, and without inhibitor.

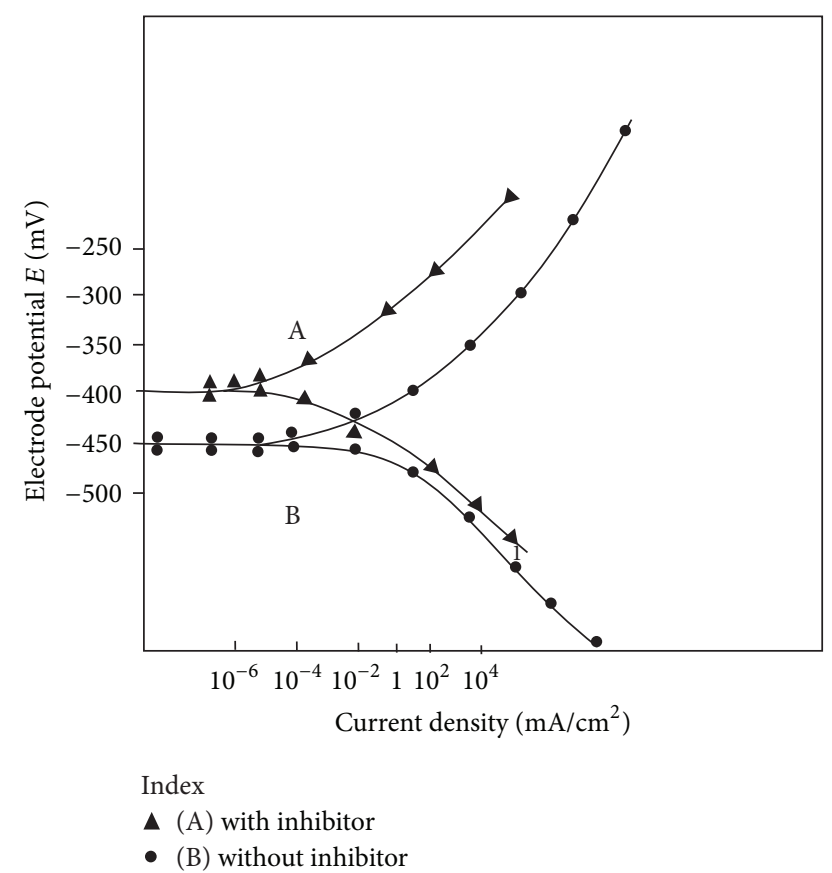

FIGURE 3: Galvanostatic polarization curves of carbon steel in $10 \%$ $\mathrm{HCl}$ with and without inhibitor.

This indicates that the formation of an inhibitor film requires some time; that is, the inhibition process has an induction period. The increased inhibition effect of NTMP may be explained on the argument that nitrogen of NTMP facilitates complex formation between metal ions coming out in the solution with NTMP and also the formation of complexed film at the metal surface.

3.2. Potentiodynamic Polarization Measurements. Figure 2 shows the results of potentiodynamic polarization measurements in the presence and absence of NTMP inhibitor in

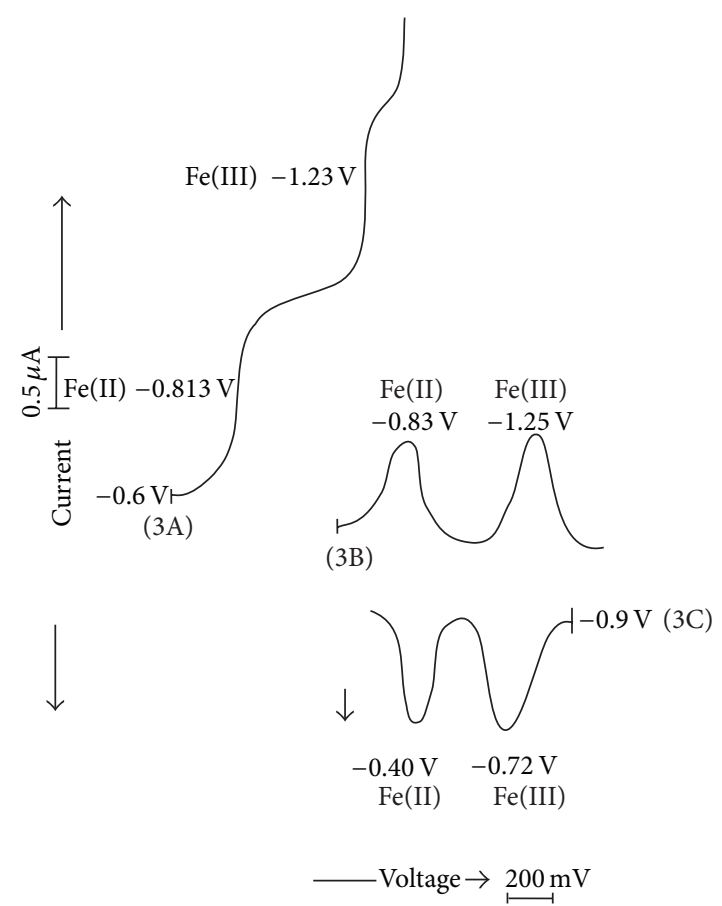

FIGURE 4: (a) Direct current polarogram, (b) Differential pulse polarogram, (c) Differential pulse anodic stripping voltammogram of corrosion solution $(10 \mathrm{~mL})$ in $0.1 \mathrm{M}$ ammonium tartrate $+0.001 \%$ gelatin at $\mathrm{pH} 9.0 \pm 0.1$ after $5 \mathrm{~min}$. of exposure.

$10 \% \mathrm{HCl}$ solution. The curve clearly shows the cathodic and anodic inhibition properties of inhibitor. It is quite clear from the curves that the corrosion potentials are more positive (anodic) than the rest of potentials. The inhibitor shows a remarked effect in lowering the current. However, in the cathodic region the effect is not significant. Thus it could be conduced that NTMP affects the anodic part of the corrosion process. Thus they work as anodic protector.

3.3. Galvanostatic Polarization Measurement. Figure 3 depicts the galvanostatic polarization curves for the corrosion of mild steel in $10 \% \mathrm{HCl}$ solution with and without NTMP inhibitor. It is clear from the figure that both anodic and cathodic currents decrease in the presence of inhibitor. However, the corrosion potentials are shifted to more electropositive values with NTMP inhibitor, but the Tafel slopes of the curves remain almost the same. The shift in corrosion potential with NTMP is $+50 \mathrm{mV}$. Thus, it could be concluded that the film formed by the inhibitor acts through the blocking effect, mainly on the anodic reaction.

3.4. Voltammetric and Polarographic Measurements. Figures 4(a), 4(b), and 4(c) are the direct current polarogram (DCP), differential pulse polarogram (DPP), and differential pulse anodic stripping voltammogram (DPASV) for corrosion sample after $5 \mathrm{~min}$ in $0.1 \mathrm{M}$ ammonium tartrate and $0.001 \%$ gelatin at $\mathrm{pH} 9.0 \pm 0.1$. The half-wave potential $\left(E_{1 / 2}\right) /$ peak potential $\left(E_{P}\right)$ values for $\mathrm{Fe}(\mathrm{II})$ and $\mathrm{Fe}(\mathrm{III})$ are $-0.81 \mathrm{~V} /-0.83 \mathrm{~V}$ and $-1.23 /-1.25 \mathrm{~V}$, respectively, in DCP/DPP 


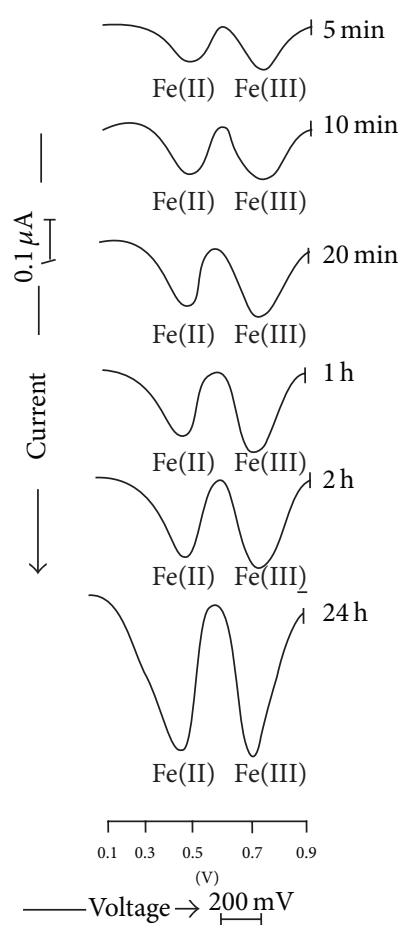

Figure 5: Differential pulse anodic stripping voltammogram of the corrosion solution of carbon steel in $10 \% \mathrm{HCl}$ at different time intervals in ammonium tartrate $+0.01 \%$ gelatin at $\mathrm{pH} 9.0 \pm 0.1$.

mode, and $E_{P}$ values are $-0.4 \mathrm{~V}$ and $-0.72 \mathrm{~V}$ for $\mathrm{Fe}(\mathrm{II})$ and Fe(III) in DPASV mode [9]. Figure 5 shows the DPASV curves of corrosion mixtures of mild steel at different time intervals. These curves show that by using voltammetric and polarographic methods, it is possible to analyze the presence of $\mathrm{Fe}(\mathrm{II})$ and $\mathrm{Fe}$ (III) in the solution, simultaneously. Fe(II) and $\mathrm{Fe}$ (III) produce two separate well-defined polarographic peaks in each case. The wave height/peak height for Fe(II) and $\mathrm{Fe}$ (III) over the whole of the working concentration range in DCP, DPP, and DPASV modes is proportional to the $\mathrm{Fe}(\mathrm{II})$ and $\mathrm{Fe}(\mathrm{III})$ concentrations. The corrosion rates at different time intervals with respect to $\mathrm{Fe}(\mathrm{II})$ and $\mathrm{Fe}$ (III) are summarized in Table 2.

Figure 6 shows the DPASV curves for the corrosion solution to which NTMP (170 mg/L) has been added. A shift in the $E_{P}$ value for each of the $\mathrm{Fe}$ (II) and $\mathrm{Fe}$ (III) indicates the M: NTMP complex formation in the solution.

Since the shift in $E_{1 / 2}$ and $E_{P}$ values of $\mathrm{Fe}$ (III) is more than that of $\mathrm{Fe}$ (II) in complexed system, it could be concluded that $\mathrm{Fe}(\mathrm{III})$ is more reactive in complex formation with NTMP than $\mathrm{Fe}(\mathrm{II})$ [10]. The corrosion rates in the presence of NTMP inhibitor have been tabulated in Table 3. A perusal of the data in Tables 1, 2, and 3 clearly shows that the rate of corrosion is very fast in the beginning of the experiment, which goes on decreasing with due course of time. The corrosion inhibition efficiency of NTMP is $55 \%, 69 \%, 75 \%, 81 \%$, and $84 \%$ after $5,10,20 \mathrm{~min}, 1$, and $2 \mathrm{~h}$, and it becomes $93 \%$ after $24 \mathrm{~h}$, respectively.

Thus, the inhibitive efficiency of NTMP (organophosphonic acid) will depend on the structure of the protective

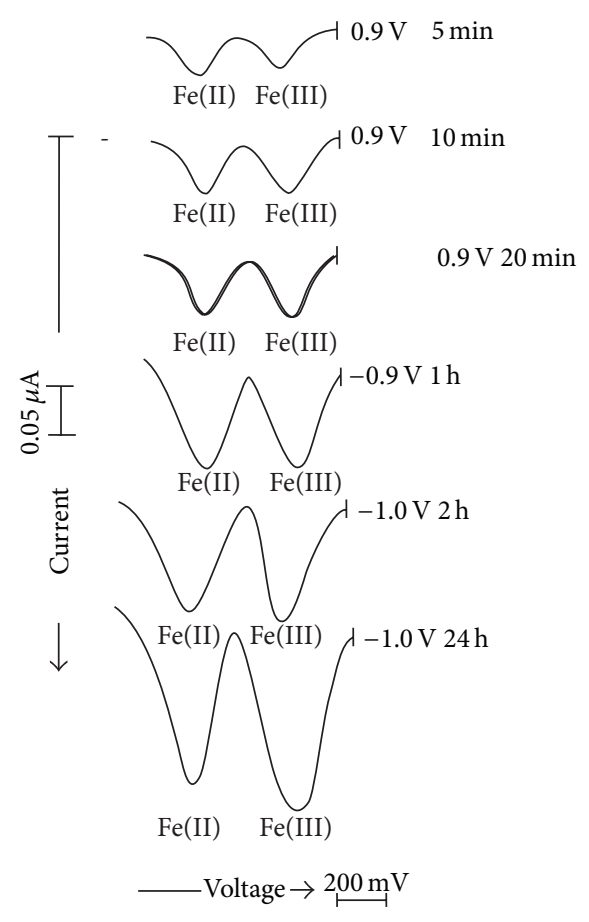

FIGURE 6: Differential pulse anodic stripping voltammogram of the corrosion solution of carbon steel, $0.1 \mathrm{M}$ ammonium tartrate + $0.001 \%$ gelatin at $\mathrm{pH} 9.0 \pm 0.1$ at different time intervals in presence of Inhibitor.

inhibitor film formed by the dissolved $\mathrm{Fe}$ (II) and Fe(III) species on the metal surface. The NTMP used as an inhibitor for the present study has the following structure:

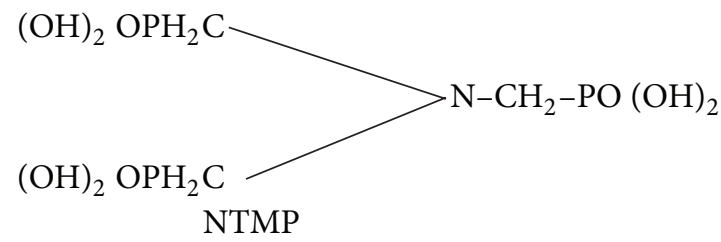

The nitrogen atom acts as the reaction centre in the complexation reaction with the metal ions.

A comparison of the corrosion rate data as calculated by gravimetric, galvanostatic, potentiodynamic polarization, and voltammetric methods clearly speaks that NTMP is a good inhibitor for corrosion inhibition of mild steel in acidic medium, that is, $10 \% \mathrm{HCl}$.

From the above data and ongoing discussion, it could be concluded that polarographic and voltammetric methods give dependable results for corrosion rates with respect to each species appearing in the solution, that is, Fe(II) and $\mathrm{Fe}$ (III). It is also clear that the proposed polarographic/voltammetric methods are highly sensitive for corrosion rate determination at short-time intervals and that too with respect to each species present in the solution, which is otherwise not possible using methods prevalent in the field of corrosion rate determination $[11,12]$ and also in the field of trace analysis, namely, atomic absorption spectrometry (AAS). 
TABLE 2: Corrosion rates with respect to concentration of Fe(II), Fe(III), and total Fe(II + III) for mild steel in $10 \% \mathrm{HCl}$ without inhibitor using voltammetric and polarographic methods.

(a) DPP mode

\begin{tabular}{|c|c|c|c|c|c|c|}
\hline \multirow{2}{*}{ Time } & \multicolumn{2}{|c|}{$\mathrm{Fe}(\mathrm{II})$} & \multicolumn{2}{|c|}{$\mathrm{Fe}(\mathrm{III})$} & \multicolumn{2}{|c|}{ Total Fe(II + III) } \\
\hline & Conc* & $\mathrm{CR}^{* *}$ & Conc $^{*}$ & $\mathrm{CR}^{* *}$ & Conc* & $\mathrm{CR}^{* *}$ \\
\hline (1) $5 \mathrm{~min}$ & 5.91 & 2.37 & 8.23 & 3.31 & 14.14 & 5.69 \\
\hline (2) $10 \mathrm{~min}$ & 6.13 & 1.23 & 9.89 & 1.99 & 16.02 & 3.22 \\
\hline (3) $20 \mathrm{~min}$ & 7.93 & 0.79 & 11.21 & 1.12 & 19.14 & 1.92 \\
\hline (4) $1 \mathrm{~h}$ & 12.16 & 0.40 & 12.55 & 0.42 & 24.17 & 0.83 \\
\hline (5) $2 \mathrm{~h}$ & 15.98 & 0.26 & 16.81 & 0.28 & 32.78 & 0.55 \\
\hline (6) $24 \mathrm{~h}$ & 50.57 & 0.07 & 56.17 & 0.07 & 107.28 & 0.15 \\
\hline
\end{tabular}

(b) DPASV mode

\begin{tabular}{|c|c|c|c|c|c|c|}
\hline \multirow{2}{*}{ Time } & \multicolumn{2}{|c|}{$\mathrm{Fe}(\mathrm{II})$} & \multicolumn{2}{|c|}{$\mathrm{Fe}(\mathrm{III})$} & \multicolumn{2}{|c|}{ Total Fe(II + III) } \\
\hline & Conc $^{*}$ & $\mathrm{CR}^{* *}$ & Conc $^{*}$ & $\mathrm{CR}^{* *}$ & Conc* & $\mathrm{CR}^{* *}$ \\
\hline (1) $5 \mathrm{~min}$ & 5.92 & 2.38 & 8.24 & 3.31 & 14.16 & 5.70 \\
\hline (2) $10 \mathrm{~min}$ & 6.15 & 1.23 & 9.87 & 1.98 & 16.02 & 3.22 \\
\hline (3) $20 \mathrm{~min}$ & 7.93 & 0.79 & 11.21 & 1.12 & 19.11 & 1.92 \\
\hline (4) $1 \mathrm{~h}$ & 12.16 & 0.40 & 12.50 & 0.42 & 24.57 & 0.82 \\
\hline (5) $2 \mathrm{~h}$ & 15.98 & 0.26 & 16.80 & 0.28 & 32.78 & 0.55 \\
\hline (6) $24 \mathrm{~h}$ & 50.57 & 0.07 & 56.17 & 0.07 & 107.28 & 0.15 \\
\hline
\end{tabular}

${ }^{*}$ Corrosion concentration $\times 10^{2}$ milligram.

${ }^{* *}$ Corrosion rate $\times 10^{2}$ milligram centimeter ${ }^{-2}$ hour $^{-1}$.

TABle 3: Corrosion rates with respect to $\mathrm{Fe}(\mathrm{II})+\mathrm{Fe}(\mathrm{III})$ for mild steel in $10 \% \mathrm{HCl}$ solution with NTMP inhibitor $(170 \mathrm{mg} / \mathrm{L})$.

\begin{tabular}{lcccccc}
\hline \multirow{2}{*}{ Time } & \multicolumn{3}{c}{ DPASV mode } & \multicolumn{3}{c}{ DPP mode } \\
& Conc $^{*}$ & CR $^{* *}$ & \% inhibition & Conc & CR $^{* *}$ & \% inibition \\
\hline (1) $5 \mathrm{~min}$ & 6.28 & 2.530 & 55.6 & 6.26 & 2.52 & 55.7 \\
(2) $10 \mathrm{~min}$ & 6.41 & 1.290 & 59.9 & 6.41 & 1.290 & 59.9 \\
(3) $20 \mathrm{~min}$ & 6.99 & 0.693 & 63.9 & 6.99 & 0.693 & 63.9 \\
(4) $1 \mathrm{~h}$ & 7.18 & 0.235 & 71.6 & 7.02 & 0.235 & 71.6 \\
(5) $2 \mathrm{~h}$ & 7.21 & 0.119 & 80.0 & 7.12 & 0.119 & 80.6 \\
(6) $24 \mathrm{~h}$ & 7.91 & 0.010 & 93.3 & 7.81 & 0.010 & 93.3 \\
\hline
\end{tabular}

${ }^{*}$ Corrosion concentration $\times 10^{2}$ milligram.

${ }^{* *}$ Corrosion rate $\times 10^{2}$ milligram centimeter ${ }^{-2}$ hour $^{-1}$.

\section{Conflict of Interests}

The authors, that is, Manish Gupta, Jyotsna Mishra, and K. S. Pitre declare that they do not have any conflict of interests regarding this paper.

\section{Acknowledgment}

The authors are thankful to the M. P. Council of Science and Technology (MPCST) Bhopal, for providing research fellowship.

\section{References}

[1] A. Singh, E. E. Ebenso, M. A. Quraishi et al., "Corrosion inhibition of carbon steel in $\mathrm{HCl}$ solution by some plant extracts," International Journal of Corrosion, vol. 2012, Article ID 897430, 20 pages, 2012.
[2] T. Horvath, E. Kalman, G. Kutsan, and A. Rauscher, "Corrosion of mild steel in hydrochloric acid solutions containing organophosphonic acids," British Corrosion Journal, vol. 29, no. 3, pp. 215-218, 1994.

[3] P. Mohan, R. Usha, G. P. Kalaighan, and V. S. Murlidharan, "Inhibition effect of benzohydrazide derivativeson corrosion behaviour of mild steel in $1 \mathrm{M} \mathrm{HCl,"} \mathrm{Journal} \mathrm{of} \mathrm{Chemistry,} \mathrm{vol.}$ 2013, Article ID 541691, 7 pages, 2013.

[4] H. Ryu, N. Sheng, T. Outsuka, S. Fugita, and H. Kajtyama, "Polypyrrole film on 55\% al-zn-coated steel for corrosion prevention," Corrosion Science, vol. 56, pp. 67-77, 2012.

[5] A. J. Freelman, Materials Performance, vol. 23, pp. 9-11, 1984.

[6] T. E. Edmonds and J. I. Guoliang, "Carbon fibre micro-electrodes in the differential pulse voltammetry of copper ions," Analytica Chimica Acta, vol. 151, pp. 99-108, 1983.

[7] A. Wachter and R. S. Treseder, "Corrosion testing evaluation of metals for process equipment," Chemical Engineering Progress, vol. 43, pp. 315-326, 1947.

[8] E. Kálmán, F. H. Kármán, J. Telegdi, B. Várhegyi, J. Balla, and T. Kiss, "Inhibition efficiency of n-containing carboxylic and carboxy-phosphonic acids," Corrosion Science, vol. 35, pp. 14771481, 1993.

[9] V. K. Chitale and K. S. Pitre, Reviews in Analytical Chemistry, vol. 6, pp. 177-184, 1982.

[10] V. Rai and K. S. Pitre, "Corrosion behaviour of carbon steel in DTPMP inhibited neutral medium," Indian Journal of Chemistry A, vol. 42, no. 1, pp. 106-108, 2003.

[11] J. Shukla and K. S. Pitre, "Corrosion and inhibition kinetics of PVA polymer on carbon steel in sulfuric acid solution," Indian Journal of Chemistry A, vol. 44, no. 11, pp. 2270-2273, 2005.

[12] J. Shukla, P. Jain, and K. S. Pitre, "Inhibitive action of thiourea plus Ca towards corrosion of brass in acidic solution," Corrosion Reviews, vol. 22, pp. 145-156, 2004. 

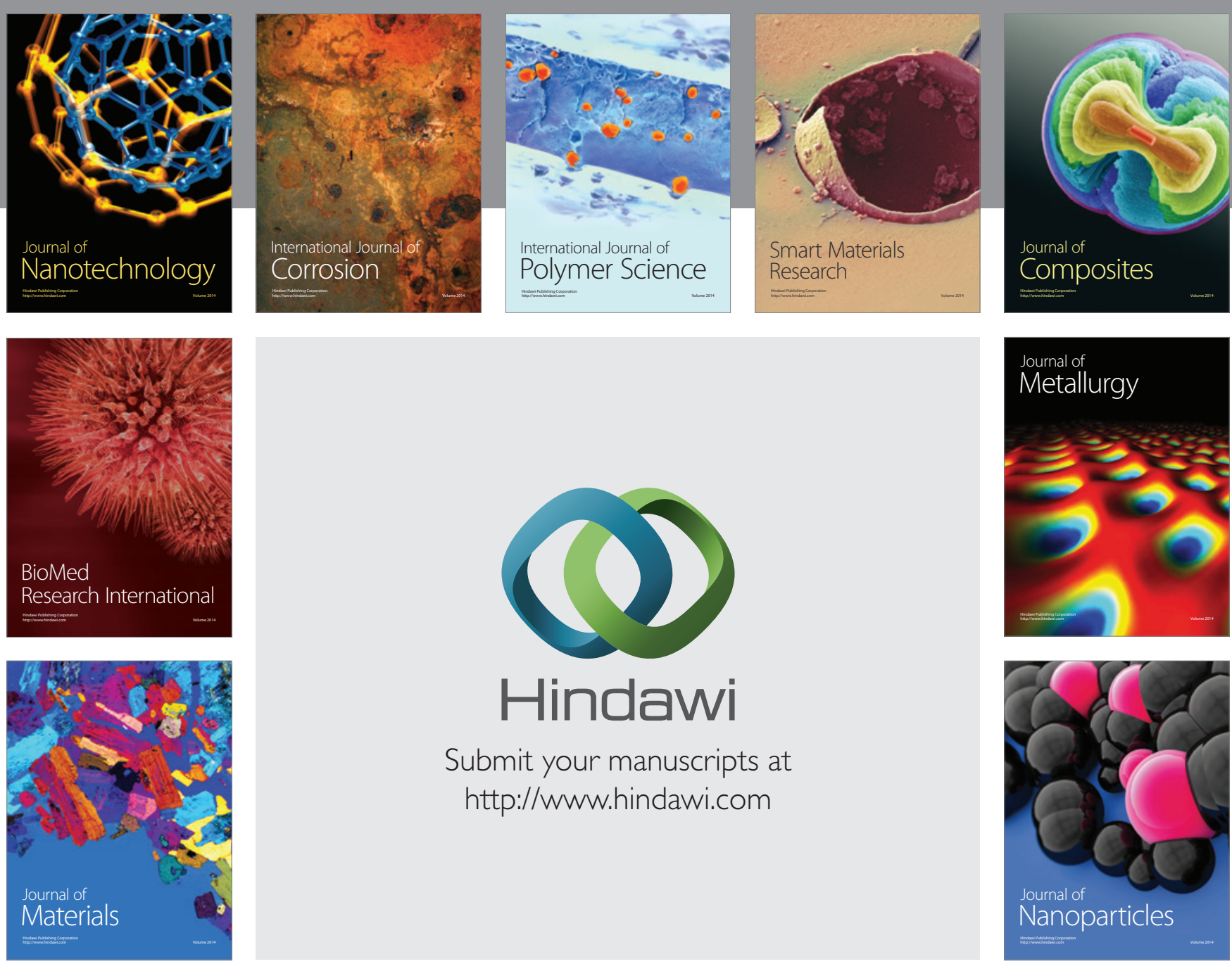

Submit your manuscripts at http://www.hindawi.com
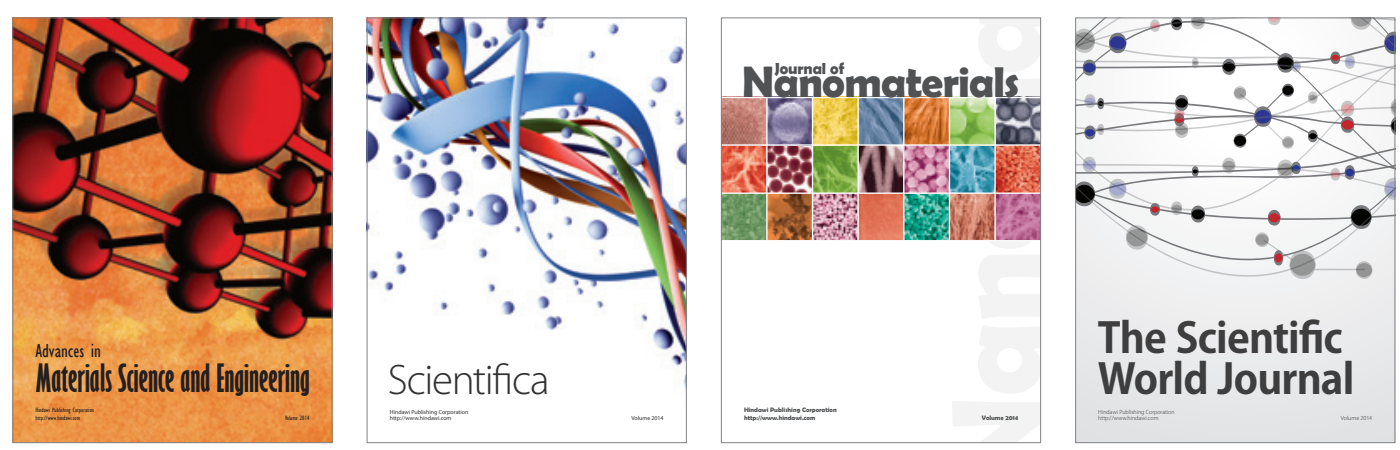

\section{The Scientific World Journal}
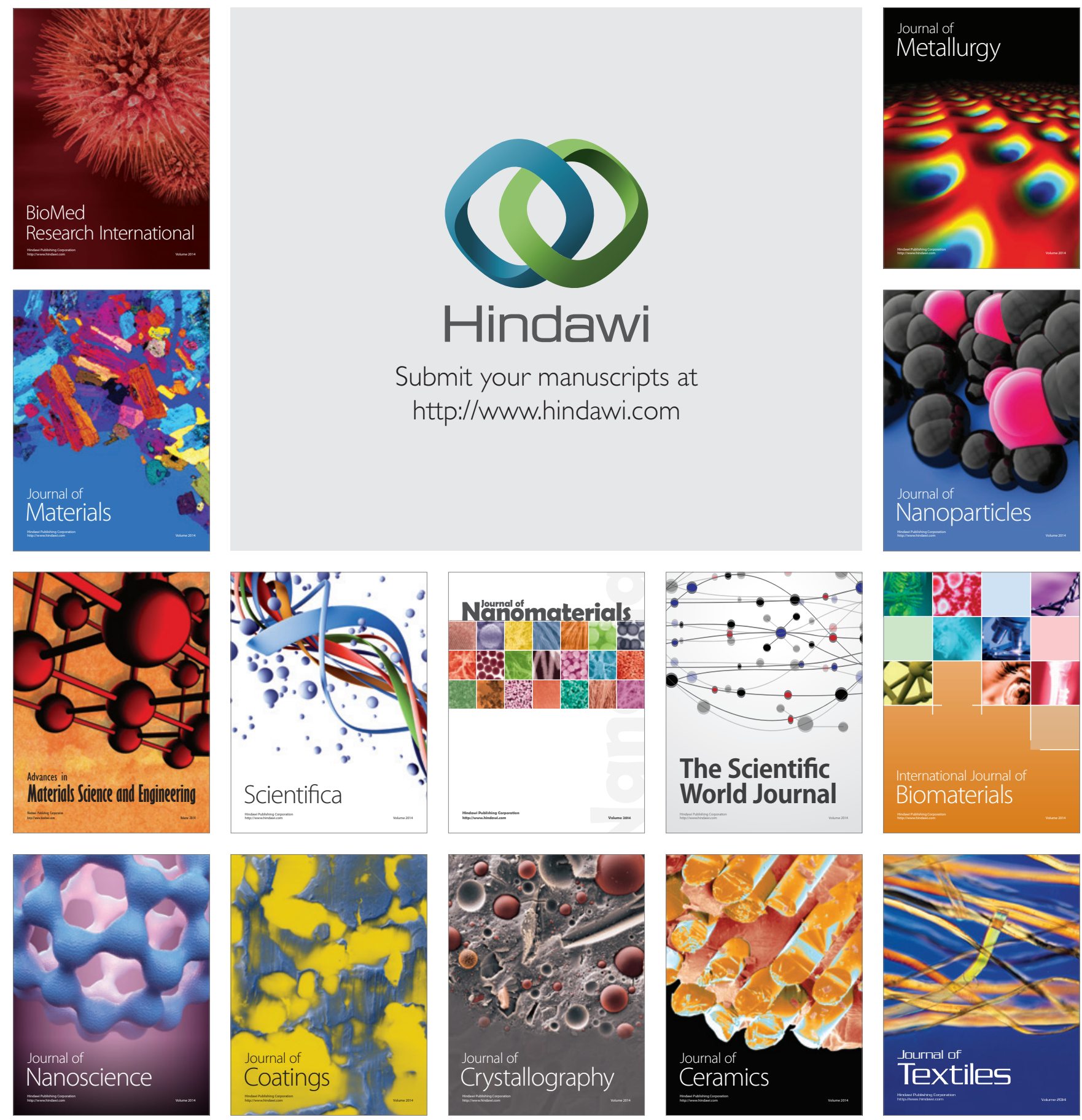